\title{
The role of surgeons on the development and performance of endoscopy
}

\author{
Kemal Dolay, Mustafa Hasbahçeci
}

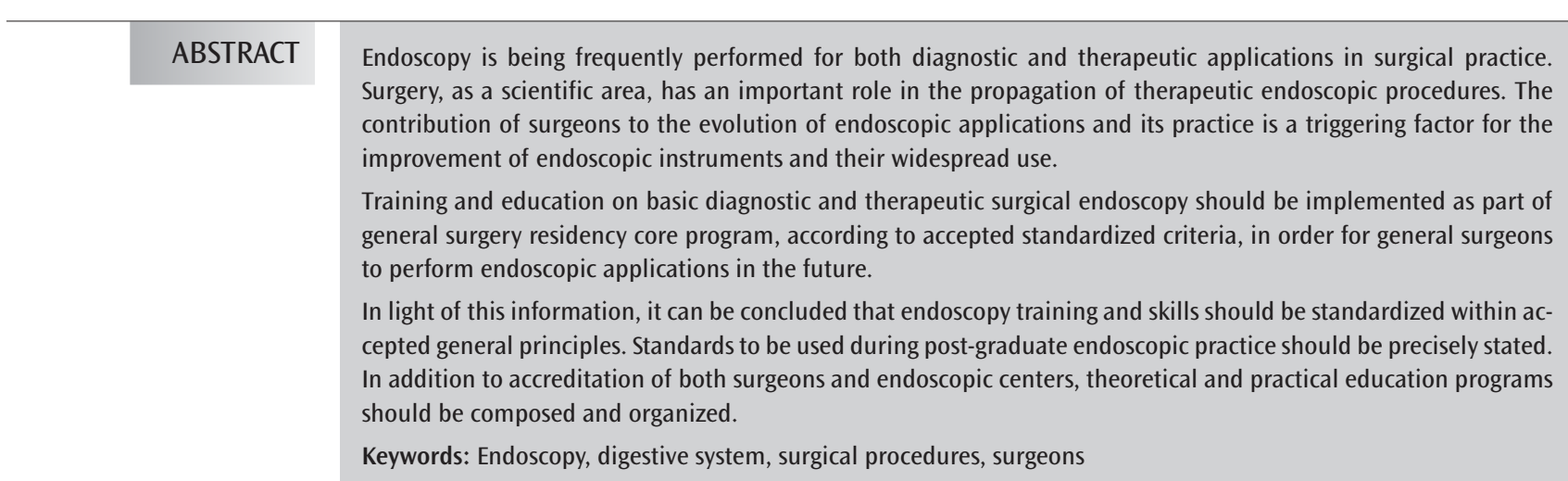

Cite this paper as: Dolay K, Hasbahçeci M. The role of surgeons on the development and performance of endoscopy. Turk J Surg 2017; 33(1): 1-4.

This study was presented at the $20^{\text {th }}$ National Surgical Congress, 13-17 April 2016, Antalya, Turkey.

Department of General Surgery, Bezmialem Vakif University School of Medicine, İstanbul, Turkey

Address for Correspondence Mustafa Hasbahçeci e-mail: hasbahceci@yahoo.com

Received: 05.10 .2016 Accepted: 18.11.2016

\section{(c) Copyright 2017} by Turkish Surgical Association

Available online at www.turkjsurg.com

\section{INTRODUCTION}

Endoscopy is an important tool both in the diagnosis and treatment of complex pathologies (1). With the development of endoscopic applications, the feasibility of diagnostic and therapeutic interventions has increased and endoscopy has become the first choice method in the diagnosis and treatment of most diseases (2). Faced with this intense need, the number of endoscopic procedures that need to be done is increasing day by day. The use of advanced endoscopic diagnosis and minimally invasive endoscopic treatment methods for the gastrointestinal system has further enhanced the importance of endoscopy-based approaches. This new situation, which is related to the widespread use of endoscopy and the development of its field of use, has also led to a new problem of who should be performing endoscopy (2). In particular, the development of surgical approaches associated with Natural Orifice Transluminal Endoscopic Surgery (NOTES), endoscopic-based treatment of gastroesophageal reflux disease, endoscopic control of gastrointestinal system bleedings, and endoscopic treatment of pancreatitis complications have become possible with the contribution of surgeons to endoscopy. Thus, the issue if endoscopy can be performed by surgeons as well as gastroenterologists should be evaluated by taking the impact of surgeons in the evolution of endoscopy into consideration.

\section{HISTORY OF ENDOSCOPY}

There are three different periods in the history of gastrointestinal endoscopy (3):

$$
\text { 1. Rigid endoscopy period (1805-1932) }
$$

\section{Semi-flexible endoscopy period (1932-1957)}

\section{Fiberoptic endoscopy (1957 and later)}

The first data related to observe inside the human body begins with the use of the rectal speculum for the treatment of rectal fistula at the time of Hippocrates (4). It took hundreds of years for these first-use tools to become useful. Light reflection has emerged as an important problem for visualizing internal regions by tubes with two open ends. Philipp Bozzini, an urologist, was the founder of today's endoscopes as the first to use an artificial light source, a mirror, with a speculum in the early $19^{\text {th }}$ century $(3,4)$. Although Bozzini's endoscopy systems have been used for vaginal, urethral, bladder and rectum imaging, its widespread use was made possible by Desormeaux (3). With the improvements in open-ended endoscopy systems, Adolf Kussmaul who was a surgeon extracted a foreign body from the esophagus using sunlight as a source of light in 1870 (5). Max Nitze introduced the idea of placing the light source with its miniaturized form to the tip of the instruments that are being used for endoscopy 
for the first time (3-5). Nitze developed the first cystoscopy in 1877 (6). Another general surgeon, Johann von Mikulicz-Radecki, was the first to perform rigid gastroscopy under morphine sedation $(7,8)$. The semi-flexible tube endoscope was first developed and used by Georg Kelling in 1898 (9). Kelling, a surgeon, performed peritoneoscopy (celioscopy) simultaneously with Dimitrij Oscarovic Ott and Hans Christian Jacobeus (10-12). The idea of placing a camera at the end of an endoscope was put into practice by Lange and Meltzing in 1898 (13). Rudolf Schindler developed the semi-flexible endoscopic instruments used by Kelling $(3,14)$. Schindler, along with Wolf, has made semi-flexible endoscopy widely available and is considered the father of gastroscopy. Basil Hirschowitz developed and used the first fiberoptic endoscopy in $1957(3,8)$. In summary, the physicians mentioned above have been the pioneers in the development of today's endoscopy systems. Following improvements in fiberoptic endoscopy systems of the upper gastrointestinal tract, colonoscopy applications for both diagnosis and treatment has gained wide acceptance.

THE ROLE OF SURGEONS IN THE EVOLUTION OF ENDOSCOPY Surgeons have been active both in the development of the concept of endoscopy and in its use for different purposes. Philipp Bozzini, the father of endoscopy, Adolf Kussmaul who used sunlight as an artificial light source and known by some authors as the father of gastroenterology, Max Nitze who developed and used cystoscopy, Johann von Mikulicz-Radecki who used rigid gastroscopy for the first time, Dimitrij Oscarovic Ott who performed the first peritoneoscopy with tube endoscopy at the same time with Georg Kelling are all surgeons who demonstratedtheir skills inthe endoscopic area as well $(8,15)$. Kussmaul was the first to use gastric tubes for therapeutic purposes. In addition, Kussmaul performed dilatation of esophageal strictures and drainage of gastric contents in case of gastric outlet obstruction by a gastric tube-pump system he developed. A gastroenterologist, Chevalier Jackson who is known as the father of broncho-esophagoscopy performed the first endoscopic gastric biopsy procedure in 1906 and was followed by Benedict, another surgeon, who developed a surgical endoscopy instrument that allowed the use of biopsy forceps in 1948 (16). Yeomans used a cystoscope through gastrotomy to control bleeding with cauterization in two patients who had previously undergone gastrotomy for palliative purposes due to hemorrhagic tumors. A German surgeon, Soehendra, described injection of sclerosing agents into bleeding gastric ulcers in 1976. The use of hypertonic saline and epinephrine for the same purpose was described by Hirao, a surgeon from Japan, in 1985.

The first endoscopic retrograde cholangiopancreatography was performed by a surgeon, McCune, in 1968 with endoscopic cannulation of the ampulla (17). This procedure has been primarily adopted as a standardized approach for surgeons for postoperative treatment of common bile duct stones after cholecystectomy and in the preoperative evaluation of patients with cholangitis or jaundice (4). Percutaneous endoscopic gastrostomy was first performed by Gauderer and Ponsky, both pediatric surgeons, in $1979(16,18)$.

Although the use of endoscopy in the lower gastrointestinal tract has gained acceptance after implementation of fiberop- polypectomy was performed by Kelly in 1895 . Shinya, a Japanese surgeon, is an important name in the introduction of colonoscopic polypectomy and intraoperative colonoscopy. Shinya has also defined the alpha loop maneuver and showed that colonoscopy can be done by a single endoscopist. Ponsky is the inventor of the concept of marking in endoscopic polypectomy. Self-expandable metal stenting for palliative purposes in colorectal cancer was performed by a Japanese surgeon, Itabashi, and elective surgery following stenting was introduced by Tamim.

\section{THE ROLE OF SURGEONS IN ENDOSCOPIC APPLICATIONS}

"Endoscopy" refers to the knowledge and experience gained by endoscopic observations, and the term "endoscopist" should be used for all physicians from both medical and surgical departments dealing with endoscopy, regardless of their specialty (19). Based on their opportunity of observing the internal structures of the human anatomy during surgery along with the susceptibility of endoscopic applications, especially of those with rigid instruments, to complications, surgeons are expected to be pioneers in the development and practice of endoscopy. If the endoscopist is a surgeon, this may aid in treatment planning by enabling evaluation of endoscopic findings along with the knowledge obtained during surgical training. It can be expected that utilization of endoscopic procedures contributes to the surgeon in treatment planning, and therefore to the patient. Furthermore, the option of endoscopic treatment in some pathological situations, besides surgical treatment, mandates that surgeons have endoscopic knowledge and competency (19).

Nevertheless, physicians other than surgeons have also been active in this field, especially with the use of flexible or fiberoptic devices. There is controversy regarding the specialty of physicians to perform endoscopic interventions or if trained nurses can take part in screening endoscopies $(20,21)$. It is believed that whether the endoscopist is a surgeon or not does not lead to a fundamental difference in the course of performing routine diagnostic endoscopic procedures (19). Due to the limited number of surgeons, multidisciplinary approaches should be established taking into account the fact and the necessity of non-surgeon physicians performing endoscopic procedures.

Therapeutic endoscopic interventions should be evaluated as a surgical procedure, and principles applied in surgical operations should be applied to these interventions. Therefore, defining the entirety of therapeutic endoscopic procedures as "surgical endoscopy" can be considered as a more appropriate term. It is more appropriate to distinguish therapeutic endoscopic procedures from diagnostic ones due to the fundamental differences between these methods (19).

There is a clear distinction among countries in terms of the extent of provision of endoscopy training during general surgery residency program and regarding the physicians belonging in which of the specialty branches to perform endoscopies. In Canada, endoscopic procedures are performed by both gastroenterologists and surgeons, but surgeons are involved in more than half of the procedures $(22,23)$. It is emphasized that an endoscopist annually performing more than 200 colonoscopies with at least $90 \%$ cecal intubation rate (at least $95 \%$ on screening colonoscopy) is required for a high quality endoscopy practice. Endoscopy training is part of the core curriculum 
in general surgery residency training across Canada. Endoscopy training is elaborated according to the years of general surgery residency training, but the number of required endoscopic procedures is not agreed upon. Therefore, it is noted that post-graduation practice should be carried out with specified standards and with special importance on education $(22,23)$. In relation to the importance of endoscopic skills in surgical practice, the American Board of Surgery has recognized endoscopy education as a fundamental component of general surgical residency training (19). Training on therapeutic endoscopic procedures is considered to be a requirement during the course of residency training (24). In European countries, there is no consensus in this respect. It is thought that in the near future, surgeons will be left behind in the practice of endoscopy in the UK since endoscopy training is generally less effective during general surgery residency than gastroenterology residency, and because there is a significant difference in postgraduate accreditation rates against surgeons (25). It is stated that major changes should be implemented in the general surgical residency core training program and that post-graduation accreditation should be emphasized. In a survey conducted among surgeons and gastroenterologists from Greece, it is reported that $22.4 \%$ of gastroenterologists believe that endoscopy is a procedure that should only be performed by gastroenterologists, and that $82 \%$ of surgeons think preoperative endoscopic imaging knowledge will assist surgeons in surgical planning (20). The authors emphasized the importance of designing endoscopy units in a way that both surgeons and gastroenterologists could work in a symbiotic environment, not as centers to be only used by gastroenterologists. In addition, distinctions are being made particularly in colonoscopy applications such as gastroenterologists and non-gastroenterologists in an attempt to create a perception that surgeons should not perform endoscopic procedures (26). However, in their colonoscopy series of 5237 cases, Mehran et al. (26) showed that general surgeons were as successful as gastroenterologists and colorectal surgeons in terms of complication and cecal intubation rates. A study by Bielawska et al. (27) showed that the risk of perforation during colonoscopy was twice as high with non-gastroenterologists than with gastroenterologists. The authors concluded that the three times higher number of procedures performed under supervision during gastroenterology training as compared to that of surgeons may have been effective in this difference. In a study by Zuckerman et al. (28) investigating the development of colorectal cancer after negative colonoscopy, they found that the risk of not detecting colorectal cancer was higher in colonoscopies performed by non-gastroenterologists. This difference was attributed to the formal gastroenterology training in the United States and Canada. A study on upper and lower gastrointestinal endoscopy training of residents conducted by a private foundation university in Turkey stated that although the training provided by the Turkish Surgical Association is a worthy solution, it was inadequate as compared to the endoscopy training given throughout the entire residency period (29). The authors emphasized that endoscopy training should be a mandatory rotation for specialist residents, which should be repeated annually, if necessary, in reference centers.

In light of this information, it can be concluded that endoscopy training and skills should be standardized within the accepted general principles both prior to and after graduation and accreditation practices should be generalized, rather than discussing to whom privileges for endoscopic applications should be granted. The applicability and monitoring of standards and the defined criteria should be debated rather than who is eligible to perform endoscopy procedures.

In this regard, in addition to the standards on endoscopy training and practice defined by international organizations such as the American Society for Gastrointestinal Endoscopy (ASGE) and the Society of American Gastrointestinal Endoscopic Surgeons (SAGES), the current status should be assessed with post-graduate seminars and annual scientific meetings, as well as establishing plans and programs for the future (19). It should not be forgotten that the future of endoscopy relies on the current practice of eligible doctors who have the knowledge and skills in endoscopy rather than who performs endoscopies. Therefore, the most important goal should be the provision and continuity of practical skills as well as knowledge in surgical endoscopic interventions, especially those for therapeutic purposes (19).

\section{CONCLUSION}

In the reality of our country, it is thought that regulations should be implemented in both training and practice of general surgeons on endoscopy in the following subjects:

The duration of basic diagnostic and therapeutic surgical endoscopy training, its distribution over the years of residency, and the number of endoscopic procedures to be performed under supervision and observation in each category should be stated in the general surgery residency core training program.

Standards to be followed during post-graduate endoscopy practice should be defined, and endoscopy centers and endoscopists should be accredited.

Theoretical and practical training programs should be held at certain intervals after graduation.

It can be suggested that supervision of the training and the implementation process by the Turkish Surgical Association, which is a higher committee, will gain wide acceptance.

Peer-review: Externally peer-reviewed.

Author Contributions: Concept - K.D., M.H.; Design - M.H., K.D.; Supervision - K.D.; Resource - K.D., M.H.; Materials - M.H., K.D.; Data Collection and/or Processing - M.H., K.D.; Analysis and/or Interpretation - M.H., K.D.; Literature Search - M.H., K.D.; Writing Manuscript - M.H., K.D.; Critical Reviews - K.D., M.H.; Other - M.H.

Conflict of Interest: No conflict of interest was declared by the authors.

Financial Disclosure: The authors declared that this study has received no financial support.

\section{REFERENCES}

1. Davis BR, Vitale GC. Endoscopy for the general surgeon. Adv Surg 2008; 42: 277-297. [CrossRef]

2. Doran H, Pătraşcu T. Endoscopy and General Surgery - Parts of the Same Activity. Chirurgia (Bucur) 2016; 111: 304-307.

3. Vázquez-Iglesias JL. Capsule endoscopy: a new era in the history of endoscopy. Rev Esp Enferm Dig 2004; 96: 3-9. [CrossRef] 
4. Berci G, Forde KA. History of endoscopy: what lessons have we learned from the past? Surg Endosc 2000; 14: 5-15. [CrossRef]

5. Kussmaul J. Uber magenspiegelung. Verb Naturforsch Ges Freiburg 1870; 5: 112.

6. Nitze M. Beobachtungs und Untersuchungsmethode fur Harnrohre Hamblase und Rectum. Wien Med Wochenschr 1879; 24: 651.

7. Mikulicz J. Uber Gastroskopie und Osophagoskopie. Wien Med Presse 1881; 45: 1405.

8. Morgenthal CB, Richards WO, Dunkin BJ, Forde KA, Vitale G, Lin E; SAGES Flexible Endoscopy Committee. The role of the surgeon in the evolution of flexible endoscopy. Surg Endosc 2007; 21: 838-853. [CrossRef]

9. Kelling G. Gegliedertes, Winklig streckbares Gastroskope rnit rotierbarem Sehprisma. Munch Med Wochenscbx 1898; 49: 1556.

10. Schollmeyer T, Soyinka AS, Schollmeyer M, Meinhold-Heerlein I. Georg Kelling (1866-1945): the root of modern day minimal invasive surgery. A forgotten legend? Arch Gynecol Obstet 2007; 276: 505-509. [CrossRef]

11. Hatzinger M, Fesenko A, Sohn M. The first human laparoscopy and NOTES operation: Dimitrij Oscarovic Ott (1855-1929). Urol Int 2014; 92: 387-391. [CrossRef]

12. Litynski GS. Laparoscopy-the early attempts: spotlighting Georg Kelling and Hans Christian Jacobaeus. JSLS 1997; 1: 83-85.

13. Lunge F, Meltzing X. Die Photography des Magininnerr. Munch Med Wochenschr 1898; 50: 1585.

14. Schindler R. Gastroscope with flexible gastroscope. Am J Dig Dis Nutr 1936; 2: 656. [CrossRef]

15. Vitardell F. Endoscopy from Bozini to Kussmaul. In: Vitardell F. Digestive Endoscopy in the Second Millenium. From the Lichtleiter to Echoendoscopy. Madrid: Thieme; 2006: pp. 21-37.

16. Achord JL. The History of Gastrointestinal Endoscopy. In: Ginsberg GG, Kochman ML, Norton ID, Gostout CJ (editors). Clinical Gastrointestinal Endoscopy. 2nd ed. St. Louis, Missouri: Elsevier Saunders; 2012. pp. 5-11. [CrossRef]

17. McCune WS, Shorb PE, Moscovitz H. Endoscopic cannulation of the ampulla of Valor: a preliminary report. Ann Surg 1968; 167: 752-756. [CrossRef]
18. Gauderer MW, Ponsky JL, Izant RJ Jr. Gastrostomy without laparotomy: a percutaneous endoscopic technique. J Pediatr Surg 1980; 15: 872-875. [CrossRef]

19. Donahue PE, Sugitani A. Gastrointestinal endoscopy and general surgical practice. Surgical endoscopy versus surgeon endoscopists. Am Surg 1991; 57: 330-333.

20. Eleftheriadis E. Should surgeons be performing flexible endoscopy? Results of a survey in Greece. Surg Endosc 1987; 1: 233-234. [CrossRef]

21. Redondo-Cerezo E, García-Cano J. Who should perform endoscopic procedures? Gut 2004; 53: 469.

22. Skubleny D, Switzer N, Karmali S, de Gara C. Endoscopy services and training: a national survey of general surgeons. Can J Surg 2015; 58: 330-334. [CrossRef]

23. Bradley NL, Bazzerelli A, Lim J, Wu Chao Ying V, Steigerwald S, Strickland M; CAGS Residents' Committee. Endoscopy training in Canadian general surgery residency programs. Can J Surg 2015; 58: 150-152. [CrossRef]

24. King N, Kunac A, Merchant AM. A Review of Endoscopic Simulation: Current Evidence on Simulators and Curricula. J Surg Educ 2016; 73: 12-23. [CrossRef]

25. Jones RP, Stylianides NA, Robertson AG, Yip VS, Chadwick G. National survey on endoscopy training in the UK. Ann R Coll Surg Engl 2015; 97: 386-389. [CrossRef]

26. Mehran A, Jaffe P, Efron J, Vernava A, Liberman MA. Colonoscopy: why are general surgeons being excluded? Surg Endosc 2003; 17: 1971-1973. [CrossRef]

27. Bielawska B, Day AG, Lieberman DA, Hookey LC. Risk factors for early colonoscopic perforation include non-gastroenterologist endoscopists: a multivariable analysis. Clin Gastroenterol Hepatol 2014; 12: 85-92. [CrossRef]

28. Zuckerman R, Doty B, Bark K, Heneghan S. Rural versus non-rural differences in surgeon performed endoscopy: results of a national survey. Am Surg 2007; 73: 903-905.

29. Manukyan MM, Severge U, Kapaklı MS, Deveci U, Oltulu M, Kebudi A. Endoscopy training of surgical residents: results of an university hospital. Ulus Cerrahi Derg 2009; 25: 101-104. 